\title{
Intracellular Regulation of the Production and Release of Human Erythroid-directed Lymphokines
}

\author{
Nicholas Dainiak and Sandra Sorba \\ Departments of Medicine and Laboratory Medicine, University of Connecticut Health Center, \\ and Connecticut Regional Red Cross, Farmington, Connecticut 06032
}

\begin{abstract}
Erythroid burst-promoting activity (BPA) is released from B lymphocytes in soluble (SBPA) and membrane-bound (mBPA) forms. To study intracellular processes involved in production of these physically separable factors, we measured their time course release into serum-free medium from $B$ cells that were pulse-exposed for 5-240 min to nonmitogenic base medium or inhibitors of energy-dependent metabolism (2,4-dinitrophenol, sodium azide, and 2-deoxy-D-glucose), transcription and translation (actinomycin D and cycloheximide), replicative DNA synthesis (cytosine arabinoside), or posttranslational processing (monensin). mBPA and sBPA were initially detectable after 1 and $2 \mathrm{~h}$, respectively. Maximum cumulative levels of $8 \pm 0.6$ and $9 \pm 1.0 \mathrm{U} / \mathrm{ml}$, respectively, were reached after $8 \mathrm{~h}$. In contrast, cumulative mBPA and $\mathrm{SBPA}$ levels in medium prepared from cells treated with metabolic inhibitors were reduced by up to $\mathbf{9 0 \%}$. Both surface exfoliation and mBPA expression by intact plasma membranes were diminished. Whereas pulse-exposure to cytosine arabinoside had no effect, treatment with actinomycin D or cycloheximide abolished BPA expression. Exposure to monensin reduced $\mathrm{mBPA}$ and SBPA levels to zero in a concentration- and time-dependent fashion. We conclude that production and release of BPA is an energy-dependent process, requiring mRNA synthesis and translation and posttranslational remodeling of the protein but not replicative DNA synthesis. ( $J$. Clin. Invest. 1991. 87:213-220.). Key words: erythropoiesis • lymphokines • membrane-bound growth factors
\end{abstract}

\section{Introduction}

Human hematopoietic stem/progenitor cells require cytokines in sufficient concentrations for differentiation and proliferation in vitro (1-3). Many of these factors are produced locally within the bone marrow by neighboring mononuclear cells $(4$, 5). Normal and transformed B lymphocytes are one source of growth regulators that are required for lineage-specific and panspecific hematopoiesis (6-9). Although the spectrum of B cell-derived biological activities has been characterized, intracellular processes resulting in the production and release of such factors are largely undefined.

In the present study we examine the time course release of erythroid-directed growth regulators into serum-free, liquid culture medium from B lymphocytes that were pulse-treated

Address reprint requests to Dr. Dainiak, University of Connecticut Health Center, 263 Farmington Avenue, Farmington, CT 06032. 1990.

Received for publication 3 April 1990 and in revised form 16 July

J. Clin. Invest.

(c) The American Society for Clinical Investigation, Inc. $0021-9738 / 91 / 01 / 0213 / 08 \quad \$ 2.00$

Volume 87, January 1991, 213-220 with specific inhibitors of cell metabolism, protein synthesis, or DNA synthesis. The results indicate that the release of soluble and membrane-associated B lymphokines is an energy-dependent process that requires active cell metabolism. Whereas mRNA synthesis, translation, and vesicular transport through the Golgi apparatus are involved in factor production and/or release, DNA synthesis is not essential for expression of these activities. Thus, erythroid growth factor synthesis and/or release involves cellular pathways that are similar to those required for endocrine hormone production $(10,11)$.

\section{Methods}

Cell collection and separation. Human plateletpheresis residues were collected from healthy volunteers for 2-3 h (model CS3000, Fenwal Inc., Ashland, MA). Informed consent was obtained before pheresis in accordance with Institutional Review Board policies. Cell concentrates were immediately diluted in minimum essential medium (MEM) (Gibco Laboratories, Grand Island, NY) with 20-U preservative-free heparin per ml, layered over Ficoll-Paque (Pharmacia, Inc., Piscataway, $\mathrm{NJ}$ ), and centrifuged at $800 \mathrm{~g}$ for $20 \mathrm{~min}$. Light-density mononuclear cells located at the interface were removed with a Pasteur pipette, resuspended, and depleted of platelets by centrifugation over sucrose (12). Platelets were removed and the washed mononuclear cells were incubated in polystyrene dishes for $60 \mathrm{~min}$ at $37^{\circ} \mathrm{C}$ to remove monocytes, and passed over a nylon wool column, as previously described (12). B lymphocytes that were $92-96 \%$ pure by surface immunophenotyping were gently dislodged from the nylon, washed, and incubated with or without inhibitor, as described below. In some experiments, monocyte-depleted, light-density mononuclear cells were rosetted with 2-amino-ethylisothiouronium bromide-treated sheep erythrocytes to remove T lymphocytes, and B cells ( $\geq 99 \%$ pure) were separated by indirect panning with mouse anti-B4 antibody (a gift of Dr. Albert Najman, Faculté de Medicine, Hôpital Saint-Antoine, Paris) as described previously (13). B lymphocytes were $>98 \%$ viable as assessed by trypan blue exclusion or by staining with ethidium bromide and acridine orange.

Approximately 1-2 ml of human bone marrow cells was aspirated from the posterior iliac crest of healthy 20-35-yr-old males and females into MEM with Hank's salts, without L-glutamine (Gibco Laboratories) plus preservative-free heparin. Informed consent was given before marrow aspiration. Light-density cells obtained after centrifugation over Ficoll-Paque were washed three times in MEM and sequentially depleted of monocytes and B lymphocytes, as described for peripheral blood cell fractionation. The resultant nonadherent, B cell-depleted marrow cells (consisting of $<1 \%$ surface Ig-positive mononuclear cells) were cultured under serum-free conditions, as previously described (14).

Assay of erythroid burst-promoting activity $(B P A)^{l}$ in serum-free bone marrow culture. Cultures were established in Iscove's modified

1. Abbreviations used in this paper: BPA, burst-promoting activity (similarly, mBPA, sBPA, and tBPA, membrane-bound, soluble, and total BPA, respectively); CM, conditioned medium; DNP, 2,4-dinitrophenol; IMDM, Iscore's modified Dulbecco's medium; P, shed membrane-derived vesicles; PM, plasma membrane vesicles; $S$, supernatants; TLCK, tosyl-L-lysine chloromethyl ketone; TPCK, L-1-tosylamide 2-phenylethyl chloromethyl ketone. 
Dulbecco's medium (IMDM, Gibco Laboratories), purified human serum albumin, transferrin, ferric chloride, and $2.0 \mathrm{U}$ recombinant human erythropoietin (70-80,000 U/mg, Amgen Biologicals, Thousand Oaks, CA) per milliliter (14). Test plates contained $9 \%$ (vol/vol) serum-free, B cell-conditioned medium (CM) or fractions thereof (see below), octylglucoside-extracted B lymphocyte plasma membranes or exfoliated surface membrane-derived vesicles (see below), or nonmitogenic base medium (IMDM). They were maintained for 10-12 d, $37^{\circ} \mathrm{C}, 5 \% \mathrm{CO}_{2}$ in humidified air. Fibrin clots were removed from incubation, fixed to glass slides with glutaraldehyde, and stained with benzidine and hematoxylin. The number of benzidine-positive erythroid bursts ( $\geq 50$ cells) in each $125 \mu l$ fibrin clot was scored. Burst-forming unit erythroid (BFU-E)-derived colony formation in cultures of 6 $\times 10^{5}$ panned marrow cells containing nonmitogenic base medium varied from 16 to 40 bursts per $1.0 \mathrm{ml}$. One unit (U) of erythroid BPA gave $100 \%$ (or twofold) stimulation above burst formation in control cultures plated with an additional 9\% IMDM.

Pulse exposure of B lymphocytes to inhibitors of cell function. B lymphocytes $\left(5 \times 10^{5} / \mathrm{ml}\right)$ were pulse-exposed for $5-240 \mathrm{~min}, 37^{\circ} \mathrm{C}$, to various concentrations of test inhibitors in serum-free IMDM or base medium alone. Inhibitors of energy-dependent cell metabolism were tested at $10^{-4}$ to $10^{-2} \mathrm{M}$. They included 2,4-dinitrophenol (DNP; Sigma Chemical Co., St. Louis, MO), an uncoupler of oxidative phosphorylation (15), sodium azide (Sigma Chemical Co.), a cytochrome oxidase blocker (16), and 2-deoxy-D-glucose (Sigma Chemical Co.). Transcription and translation inhibitors were tested at $10-100 \mu \mathrm{g} / \mathrm{ml}$, and included actinomycin D (Sigma Chemical Co.), an inhibitor of messenger RNA synthesis, and cycloheximide (Sigma Chemical Co.), an antibiotic that inhibits peptidyl transferase activity (17). Monensin (Sigma Chemical Co.), a carboxylic ionophore which interferes with vesicular traffic of newly synthesized peptides through the Golgi apparatus and terminal glycosylation (18), was employed at $10^{-9}$ to $10^{-6} \mathrm{M}$ as an inhibitor of posttranslational processing. To determine whether monensin alters BPA expression after its release from lymphocytes, $10^{-9}$ or $10^{-8} \mathrm{M}$ of the drug was incubated with $\mathrm{CM}$ for up to $14 \mathrm{~h}$ and residual activity was assayed in the $\mathrm{CM}$ after exhaustive dialysis against PBS (see below). Cytosine arabinoside (Sigma Chemical Co.), an analogue of 2'-deoxycytidine, was used as an inhibitor of replicative DNA synthesis at concentrations of $10^{-8}$ to $10^{-6} \mathrm{M}$.

Extraction of BPA from plasma membranes and shed vesicles. Plasma membranes and membrane vesicles exfoliated into $\mathrm{CM}$ from the surface of control and test B lymphocytes were purified, detergent treated, and assayed for extractable BPA, as previously described (19, $20)$. Briefly, 2 vol of control or test whole cells were loaded with 1 vol $90 \% \mathrm{wt} / \mathrm{vol}$ glycerol in PBS, disrupted in a Dounce homogenizer, and subjected to isopycnic centrifugation and sucrose centrifugation. Resultant plasma membrane vesicles (PM) and shed membrane-derived vesicles $(P)$ were sequentially extracted with $0.1 \mathrm{~N} \mathrm{NaOH}$ and 30 $\mathrm{mmol} /$ liter $n$-octyl $\beta$-D-glucopyranoside (Sigma Chemical Co.). Solubilized $\mathrm{PM}$ and $\mathrm{P}$ membranes were stored at $4^{\circ} \mathrm{C}$ until use in culture for assay of membrane-associated BPA (mBPA).

Preparation and fractionation of conditioned medium. After treatment, B cells were washed three times in IMDM, resuspended to a density of $5 \times 10^{6} / \mathrm{ml}$ IMDM containing L-glutamine, penicillin, and streptomycin (Gibco Laboratories) in $25-\mathrm{cm}^{2}$ tissue culture flasks (Corning Glass Works, Corning, NY) and incubated for 1, 2, 4, 8, or 14 h at $37^{\circ} \mathrm{C}, 5 \% \mathrm{CO}_{2}$ in humidified air. In some cases, the serine and thiol protease inhibitors leupeptin $\left(10^{-4} \mathrm{M}\right.$; Sigma Chemical Co.), aprotinin ( $35 \mathrm{U} / \mathrm{ml}$; Sigma Chemical Co.), phenylmethylsulfonyl fluoride (PMSF, $10^{-5} \mathrm{M}$; Sigma Chemical Co.), L-1-tosylamide 2-phenylethyl chloromethyl ketone (TPCK, $10^{-5} \mathrm{M}$; Sigma Chemical Co.) and/or tosyl-L-lysine chloromethyl ketone (TLCK, $10^{-5} \mathrm{M}$; Sigma Chemical Co.) were also added. CM was freed of cells by centrifugation at $800 \mathrm{~g}$ for $20 \mathrm{~min}$, and dialyzed, 48-72 h, against PBS ( $5 \mathrm{mmol} /$ liter sodium phosphate, $150 \mathrm{mmol} /$ liter sodium chloride, $\mathrm{pH} \mathrm{7.6)} \mathrm{to} \mathrm{remove} \mathrm{resid-}$ ual inhibitors. CM was separated into supernatants or $\mathrm{CM}(\mathrm{S})$ and plasma membrane-derived vesicle containing pellets or $\mathrm{CM}(\mathrm{P})$ by centrifugation at $40,000 \mathrm{~g}$ for $40 \mathrm{~min}$, as previously described (19). Super- natants were filter-sterilized (Millipore Corp., Bedford, MA), and pellets were resuspended in a minimal volume of PBS. Unseparated CM, $\mathrm{CM}(5)$, and $\mathrm{CM}(\mathrm{P})$ were stored at $4^{\circ} \mathrm{C}$ until use in culture for assay of total BPA (tBPA), soluble BPA (sBPA), and mBPA, respectively.

Protein determination. Amounts of protein present in intact plasma membranes and shed, extracellular membrane-derived vesicles were quantitated by the method of Lowry et al. (21) using a BSA standard. Protein measurements were verified by the fluorescamine method (22). Although precise data are unavailable, it is expected that $<0.1 \%$ of total plasma membrane and extracellular membrane vesicle protein is represented by BPA.

Statistical analysis. Mean \pm SE bursts in quadruplicates were compared by the two-sample ranks test of Wilcoxon and White (23).

\section{Results}

Kinetics of BPA release from untreated cells. Release of BPA from highly purified lymphocytes incubated in base medium was determined as a function of time. As shown in Fig. $1 a$, this lymphokine is released within $1 \mathrm{~h}$, and reaches a maximum cumulative level by $8 \mathrm{~h}$ of incubation. The appearance of activ-
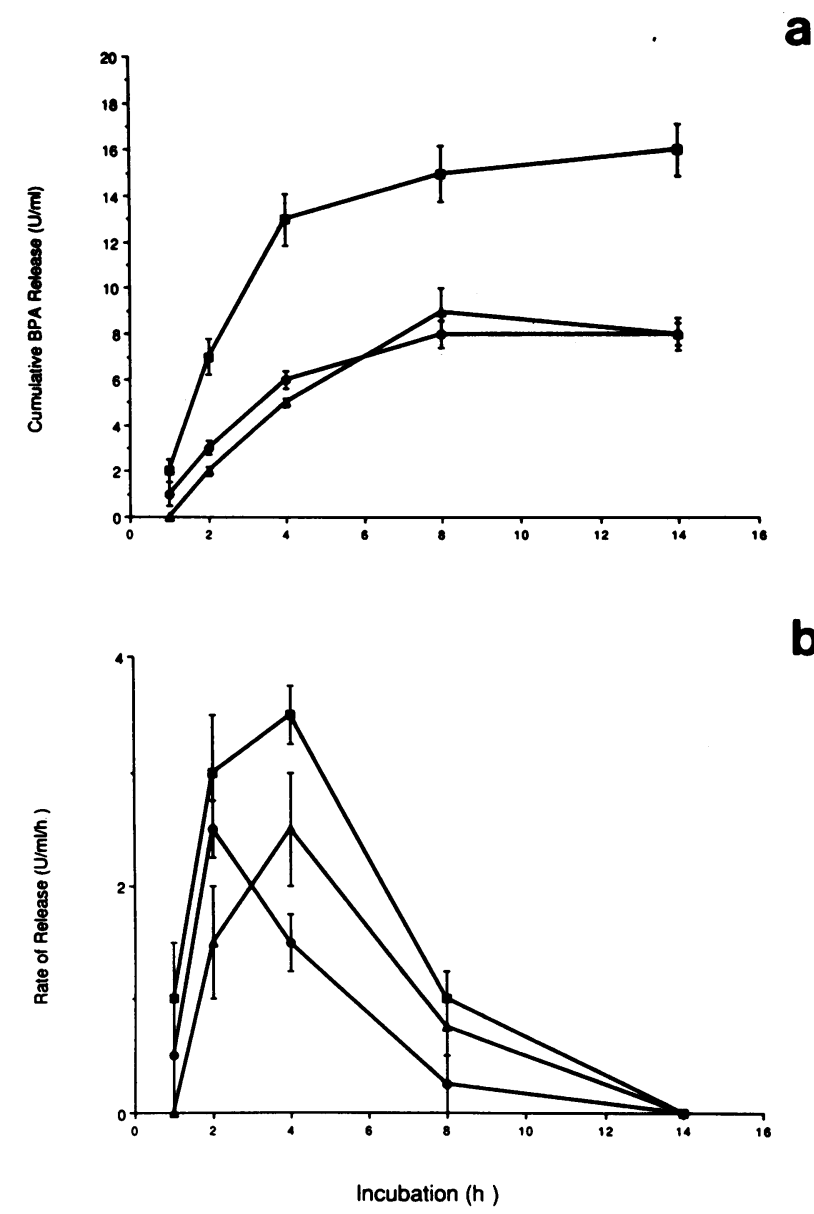

Figure 1. BPA release from untreated B lymphocytes. (a) Mean \pm SE BPA released into unseparated CM ( $\bullet$ ), CM supernatants ( $\triangle$ ), and membrane vesicle-containing pellets (๑). At $1 \mathrm{~h}$ virtually all BPA present in CM (tBPA) is due to activity associated with shed vesicles (mBPA). Cultures with nonmitogenic base medium contained $24 \pm 3$ bursts $/ 6 \times 10^{5}$ cells per $1.0 \mathrm{ml}$. B cells were purified to a level of

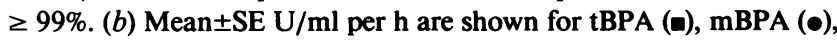
and SBPA (ه). Peak BPA release occurs at $4 \mathrm{~h}$, and no additional BPA release occurs by $14 \mathrm{~h}$ of incubation. 
Table I. Influence of Protease Inhibitors on Cumulative BPA Levels

\begin{tabular}{lccc}
\hline \multicolumn{1}{c}{ Inhibitor } & tBPA & $\mathrm{mBPA}$ & $\mathrm{sBPA}$ \\
\hline & & $\mathrm{U} / \mathrm{ml}$ & \\
None & $14.5 \pm 1.9$ & $6.3 \pm 1.0$ & $6.9 \pm 1.2$ \\
Aprotinin & $13.8 \pm 0.7$ & $6.5 \pm 0.8$ & $6.4 \pm 1.1$ \\
Leupeptin & $14.0 \pm 1.3$ & $5.9 \pm 0.7$ & $7.1 \pm 0.7$ \\
$\begin{array}{l}\text { Aprotnine + Leupeptin + TPCK } \\
\quad \text { TLCK + PMSF }\end{array}$ & $13.7 \pm 0.5$ & $5.8 \pm 0.6$ & $6.3 \pm 1.2$ \\
& & & \\
\hline
\end{tabular}

B cells were incubated in the absence (none) and presence of protease inhibitors for $14 \mathrm{~h}$ at $37^{\circ} \mathrm{C}$. CM was harvested, fractionated into vesicle-containing pellets and supernatants, and assayed for $\mathrm{tBPA}$ (in unseparated CM), mBPA, and SBPA, as described in Methods. Means \pm SE are displayed.

ity in $\mathrm{CM}(\mathrm{P})$ precedes that of $\mathrm{CM}(\mathrm{S})$ by $\sim 1 \mathrm{~h}$ (see Fig. $1 a$ ). The sum of activity in $\mathrm{CM}(\mathrm{P})$ and $\mathrm{CM}(\mathrm{S})$ approximates total activity present in unseparated CM (tBPA). Addition of nontoxic protease inhibitors during the conditioning process did not alter BPA levels in either unseparated CM or CM fractions (Table I). Similar results were obtained when combinations of protease inhibitors were employed.

The rate of BPA release peaked at $3.5 \pm 0.3 \mathrm{U} / \mathrm{ml}$ per $\mathrm{h}$ at $4 \mathrm{~h}$ of incubation (see Fig. $1 \mathrm{~b}$ ). Peak rate of release of $\mathrm{mBPA}$ $(2.5 \pm 0.2 \mathrm{U} / \mathrm{ml}$ per $\mathrm{h})$ preceded that of $\mathrm{sBPA}$ release $(2.4 \pm 0.3$ $\mathrm{U} / \mathrm{ml}$ per $\mathrm{h}$ ), as shown in Fig. $1 b$. Together, the data indicate that the time course release of BPA is similar to that of the release of other lymphokines $(24,25)$, and is also consistent with BPA release from unseparated lymphocytes (13).

Energy requirement for BPA production. Inhibitors of energy-dependent metabolism $(0.1 \mathrm{mM}$ DNP, $10 \mathrm{mM}$ sodium azide, or $10 \mathrm{mM}$ deoxyglucose) were preincubated with $\mathrm{B}$ lymphocytes that were washed and, subsequently, used as a source of BPA. As shown in Fig. 2, cumulative tBPA levels in CM harvested after $14 \mathrm{~h}$ of incubation were reduced by $\geq 30 \mathrm{~min}$ exposure to each inhibitor (relative to control, $P<0.05$ or less). Peak rates of tBPA release at $4 \mathrm{~h}$ of incubation from treated cells were approximately one-half that of tBPA release from untreated cells: $1.5 \pm 0.2,1.2 \pm 0.3$, and $1.5 \pm 0.3 \mathrm{U} / \mathrm{ml}$ per $\mathrm{h}$ for cells pulse-exposed for $30 \mathrm{~min}$ to DNP, sodium azide, or deoxyglucose, respectively. Both sBPA and mBPA concentrations were similarly diminished (data not shown).

The tBPA level in medium conditioned by cells incubated with base medium alone for $120 \mathrm{~min}$ (see Fig. 2) was reduced to a level (from $14.2 \pm 0.8 \mathrm{U} / \mathrm{ml}$ at $5 \mathrm{~min}$ to $9.0 \pm 0.8 \mathrm{U} / \mathrm{ml}$ at 120 min) that is consistent with production of BPA (see tBPA release at $2 \mathrm{~h}$ of $7.0 \pm 0.8 \mathrm{U} / \mathrm{ml}$ in Fig. $1 \mathrm{a}$ ) and subsequent removal of BPA after control lymphocytes were pelleted and resuspended in an identical fashion as performed with test lymphocytes. In contrast, tBPA levels of $0.8 \pm 0.4,0.5 \pm 0.5$, and $1.0 \pm 0.7 \mathrm{U} / \mathrm{ml}$, respectively, were measured in test medium prepared from cells pulse-exposed for $120 \mathrm{~min}$ to DNP, sodium azide, or deoxyglucose, respectively (relative to control, $P$ $<0.05$ for each).

Exfoliation of $m B P A$ requires cell metabolism. Although it is well established that normal and malignant mammalian cells exfoliate surface membrane components $(26,27)$, little is known concerning cellular requirements for this physiologic process. To determine whether metabolic energy is required for exfoliation, membrane protein shedding from cells incubated with medium alone or inhibitors of energy-dependent metabolism was quantified after 2,4 , or $14 \mathrm{~h}$ of incubation. Fig. 3 shows that exposure to metabolic inhibitors for $120 \mathrm{~min}$ results in dramatic reduction in plasma membrane-derived vesicles present in $\mathrm{CM}(\mathrm{P})$ (relative to control, $P<0.05$ at each time point). The rate of membrane shedding into the $\mathrm{CM}(\mathrm{P})$ of treated and control cells was similar with respect to time (peak release at $2 \mathrm{~h}$ for all groups) and protein concentration over time (peak rate of $15 \pm 2 \mu \mathrm{g} / \mathrm{ml}$ per $\mathrm{h}$ for control cells vs. $13 \pm 1$, $14 \pm 2$, and $13 \pm 2 \mu \mathrm{g} / \mathrm{ml}$ per $\mathrm{h}$ for cells pulse-exposed to DNP,

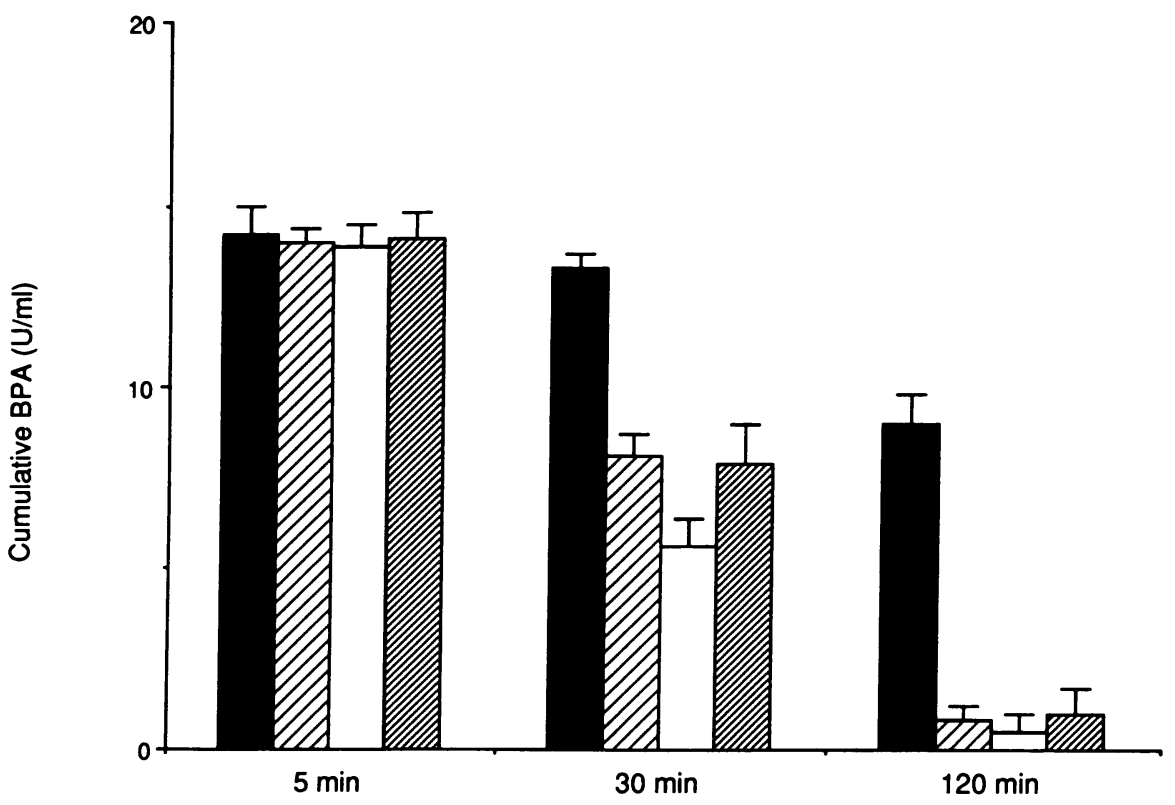

Preincubation Time
Figure 2. Effects of metabolic inactivation on tBPA release. B lymphocytes were pulse-exposed for the indicated periods of time to IMDM alone (solid bars), $0.1 \mathrm{mM}$ DNP (coarse hatched bars), $10 \mathrm{mM}$ sodium azide (open bars), or $10 \mathrm{mM}$ deoxyglucose (fine hatched bars). Shown are mean $\pm \mathrm{SE}$ levels measured in $\mathrm{CM}$ after $14 \mathrm{~h}$ of incubation. Relative to levels in control $\mathrm{CM}$, activity is reduced after 30 or $120 \mathrm{~min}$ of exposure to inhibitor ( $P<0.05$ for each). 


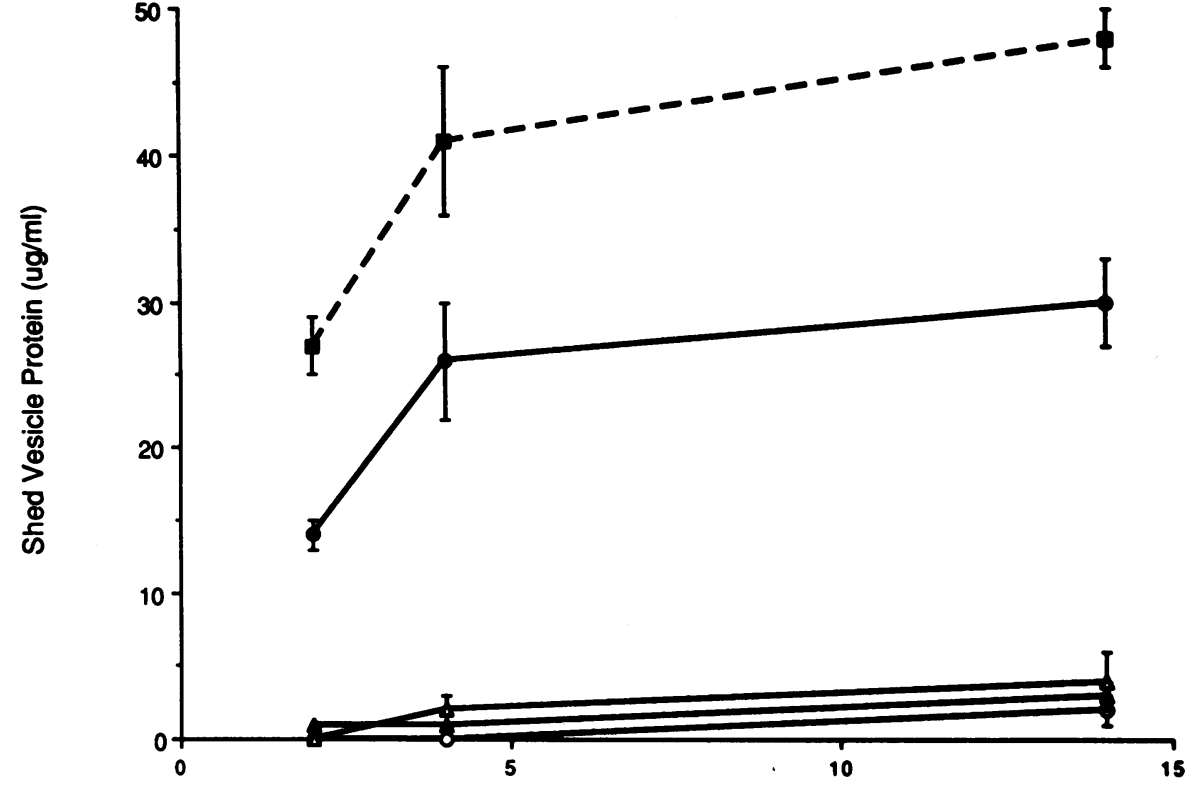

Incubation (h)
Figure 3. Effect of metabolic inhibitors on cell surface exfoliation. B lymphocytes were pulse-exposed for $120 \mathrm{~min}, 37^{\circ} \mathrm{C}$, to IMDM alone (treated control, $\bullet$ ), $0.1 \mathrm{mM}$ DNP ( $\triangle), 10 \mathrm{mM}$ sodium azide (O), or 10 $\mathrm{mM}$ deoxyglucose $(\Delta)$, and resuspended in fresh culture medium. Amounts of vesicle protein appearing in $\mathrm{CM}(\mathrm{P})$ over time were measured and compared to activity present in untreated control cells ( $\square$ ). Reduction in shed protein in treated control $\mathrm{CM}(\mathrm{P})$ relative to untreated control $\mathrm{CM}(\mathrm{P})$ is consistent with removal of membrane vesicles that shed early (i.e., after $2 \mathrm{~h}$ ) into liquid medium (see reference 13 ). sodium azide, and deoxyglucose, respectively). Moreover, expression of mBPA per microgram of plasma membrane or shed extracellular membrane vesicles was also reduced (Table II). Taken together, the data suggest that growth factor localization to the plasma membrane and exfoliation from the cell surface require active cell metabolism.

Level of regulation of BPA synthesis. To assess the level of regulation of BPA synthesis, B cells were pulse-exposed to base medium or inhibitors of transcription, translation, or DNA synthesis. As shown in Table III, even brief $(5 \mathrm{~min})$ treatment with actinomycin $D$ or cycloheximide reduced the levels of mBPA and sBPA recovered in CM after $14 \mathrm{~h}$ of incubation to zero. tBPA, mBPA, and sBPA released into $C M$ after $1,2,4$, or $8 \mathrm{~h}$ of incubation were also undetectable in CM prepared from treated cells. At a concentration of $10 \mu \mathrm{g}$ of cycloheximide $/ \mathrm{ml}$, levels of tBPA, mBPA, and sBPA were barely detectable (relative to control, $P<0.05$ ) (data not shown).
In contrast, pulse-exposure of B cells to cytosine arabinoside for as long as $120 \mathrm{~min}$ had no effect on the expression of sBPA or mBPA in dialyzed CM harvested after $14 \mathrm{~h}$ of incubation (Table IV). This observation is of interest since mitogens are frequently added during incubation of lymphoid cells for the preparation of cytokine-containing $\mathrm{CM}$.

Intracellular processing of BPA. Column-purified BPA migrates as a broad "band" on tightly crosslinked SDS gels, consistent with the charge heterogeneity of glycoproteins (19). Therefore, we assessed the involvement of the Golgi apparatus in the processing of BPA by using monensin, an agent that interferes with transport of proteins through this organelle. Fig. 4 shows that monensin pretreatment results in dose-dependent and time-dependent reduction in tBPA released into $\mathrm{CM}$ after $14 \mathrm{~h}$. Whereas $10^{-9} \mathrm{M}$ of the drug showed no effect, $10^{-8} \mathrm{M}$ reduced activity from $12.4 \pm 0.9$ to $2.1 \pm 0.6 \mathrm{U} / \mathrm{ml}(P<0.05)$. An equal reduction in mBPA and sBPA was observed (Fig. $4 a$ ). In

Table II. Effects of Metabolic Inhibition on Specific Activity of $\mathrm{mBPA}$

\begin{tabular}{|c|c|c|c|c|c|c|}
\hline \multirow{2}{*}{$\begin{array}{l}\text { Membrane } \\
\text { preparation }\end{array}$} & \multirow{2}{*}{$\begin{array}{c}\text { Incubation } \\
\text { time }\end{array}$} & \multirow[b]{2}{*}{ Base medium } & \multicolumn{4}{|c|}{ Inhibitors } \\
\hline & & & DNP & $\mathrm{Na}$ azide & Deoxyglucose & Monensin \\
\hline & $h$ & & & $U / \mu g$ & & \\
\hline \multirow[t]{3}{*}{$\mathbf{P M}$} & 2 & $0.31 \pm 0.10$ & $0.6 \pm 0.02$ & $0.07 \pm 0.03$ & $0.06 \pm 0.01$ & - \\
\hline & 4 & $0.29 \pm 0.14$ & $0.04 \pm 0.02$ & $0.10 \pm 0.05$ & $0.07 \pm 0.04$ & - \\
\hline & 14 & $0.26 \pm 0.11$ & $0.05 \pm 0.01$ & $0.06 \pm 0.02$ & $0.08 \pm 0.05$ & $0.01 \pm 0.01$ \\
\hline \multirow[t]{3}{*}{$\mathbf{P}$} & 2 & $0.39 \pm 0.15$ & $0.10 \pm 0.03$ & $0.08 \pm 0.01$ & $0.09 \pm 0.03$ & - \\
\hline & 4 & $0.41 \pm 0.09$ & $0.09 \pm 0.02$ & $0.10 \pm 0.03$ & $0.04 \pm 0.01$ & - \\
\hline & 14 & $0.34 \pm 0.12$ & $0.06 \pm 0.02$ & $0.10 \pm 0.03$ & $0.07 \pm 0.03$ & $0.03 \pm 0.02$ \\
\hline
\end{tabular}

Highly purified B cells were incubated with nonmitogenic base medium, $0.1 \mathrm{mM}$ DNP, $10 \mathrm{mM}$ sodium azide, $10 \mathrm{mM}$ deoxyglucose, or $10^{-8} \mathrm{M}$ monensin (+ inhibitors) for $120 \mathrm{~min}$ at $37^{\circ} \mathrm{C}$. They were pelleted, washed, and used to prepare intact plasma membranes (PM) and CM after a 2-, 4-, or 14-h incubation. Shed vesicles were recovered from pellets of CM. The amounts of $\mathrm{mBPA}$ and protein sequentially extracted with $\mathrm{NaOH}$ and $n$-octyl $\beta$-D-glucopyranoside from $\mathrm{PM}$ and $\mathrm{P}$ were measured, and specific activity was calculated. Results are recorded as mean $\pm \mathrm{SE}$ in quadruplicate experiments. In each case, the value in test PM or $P$ is lower than that in control samples at the $\leq 0.05$ level. 
Table III. Effects of Transcription Inhibitors on BPA Expression

\begin{tabular}{lccr}
\hline \multicolumn{1}{c}{$\begin{array}{c}\text { Preincubation time } \\
\text { (min) }\end{array}$} & $\begin{array}{c}\text { Inhibitor } \\
\text { concentration }\end{array}$ & mBPA & sBPA \\
\hline & $\mu g / m l$ & \multicolumn{2}{c}{$U / m l$} \\
Control (5) & 0 & $8.2 \pm 0.5$ & $7.5 \pm 1.0$ \\
Control (30) & 0 & $8.0 \pm 0.4$ & $7.0 \pm .07$ \\
Control (120) & 0 & $6.5 \pm 0.7$ & $6.2 \pm 1.1$ \\
Actinomycin (5) & 10 & $0.0 \pm 0.0$ & $0.0 \pm 0.0$ \\
Actinomycin (30) & 10 & $0.0 \pm 0.0$ & $0.0 \pm 0.0$ \\
Actinomycin (120) & 10 & $0.0 \pm 0.0$ & $0.0 \pm 0.0$ \\
Cycloheximide (5) & 100 & $0.0 \pm 0.0$ & $0.0 \pm 0.0$ \\
Cycloheximide (30) & 100 & $0.0 \pm 0.0$ & $0.0 \pm 0.0$ \\
Cycloheximide (120) & 100 & $0.0 \pm 0.0$ & $0.0 \pm 0.0$ \\
& & & \\
\hline
\end{tabular}

B cells were incubated with base medium (control) or inhibitor for $120 \mathrm{~min}$ at $37^{\circ} \mathrm{C}$. Viability was $\geq 95 \%$ at end of preincubation by exclusion of Trypan blue and staining with acridine orange and ethidium bromide.

contrast, monensin had no effect on tBPA expression after its release into $\mathrm{CM}$ (Fig. 4 b), suggesting that monensin-mediated reduction in BPA levels is due to impaired processing rather than to modification of a fully processed molecule. As shown in Table II, specific activity of the growth factor was reduced in both shed vesicles and intact plasma membranes derived from monensin-treated cells.

\section{Discussion}

Hematopoietic-specific growth factors are endocrines and paracrines whose primary action is to control progenitor/stem cell proliferation in a receptor-dependent fashion $(2,3,5)$. In this respect, they are similar to other polypeptide growth factors and oncogene products whose hormone-like action is initiated by receptor interaction (28). Many of the latter regulators of cell viability and growth have been found to alter hematopoietic stem/progenitor cell proliferation, including platelet-de-

Table IV. Effects of Cytosine Arabinoside on BPA Expression

\begin{tabular}{lccc}
\hline $\begin{array}{c}\text { Preincubation time } \\
\text { (min) }\end{array}$ & Concentration & $\mathrm{mBPA}$ & $\mathrm{sBPA}$ \\
\hline & $M$ & & $\mathrm{U} / \mathrm{ml}$ \\
& & & \\
Control (5) & 0 & $8.4 \pm 0.9$ & $7.8 \pm 2.1$ \\
Control (30) & 0 & $8.0 \pm 0.6$ & $7.5 \pm 0.8$ \\
Control (120) & 0 & $5.9 \pm 2.0$ & $5.6 \pm 1.2$ \\
Inhibitor (5) & $10^{-8}$ & $8.8 \pm 0.4$ & $7.9 \pm 0.4$ \\
Inhibitor (30) & $10^{-8}$ & $8.1 \pm 0.7$ & $6.8 \pm 0.7$ \\
Inhibitor (120) & $10^{-8}$ & $5.9 \pm 0.8$ & $5.9 \pm 0.5$ \\
Inhibitor (5) & $10^{-7}$ & $8.2 \pm 1.0$ & $8.0 \pm 1.2$ \\
Inhibitor (30) & $10^{-7}$ & $7.9 \pm 0.9$ & $7.8 \pm 0.8$ \\
Inhibitor (120) & $10^{-7}$ & $5.7 \pm 1.5$ & $5.5 \pm 0.4$ \\
& & &
\end{tabular}

B cells were pretreated for $120 \mathrm{~min}$ at $37^{\circ} \mathrm{C}$ with base medium (control) or cytosine arabinoside (inhibitor) at the indicated concentrations. Cells were washed and resuspended in base medium for $14 \mathrm{~h}$ at $37^{\circ} \mathrm{C}$. CM was harvested, fractionated, and assayed for BPA, as described in Methods. rived growth factor (29-31), insulin-like growth factors I and II (32-34), transforming growth factors (35), and a variety of "public" hormones whose actions are diverse and whose target cells are widely distributed throughout the body (36). Peripheral blood, bone marrow, and splenic lymphocytes represent another source of hematopoietic growth factors. Here, we have examined cellular mechanisms involved in the production and release of the human lymphokine BPA, a factor previously purified in this laboratory (20), and found by the investigators to be biochemically and immunologically distinct from other hematopoietic cytokines, including interleukin 3 and erythroid potentiating activity $(8,20,37)$. The results indicate that pathways utilized for BPA production are analogous to those involved in peptide hormone synthesis by cells of endocrine glands.

To examine the level of regulation of BPA synthesis/release, the effects of various agents known to interfere with replicative DNA, mRNA, and protein synthesis on BPA production was determined. The results demonstrate that the transcription inhibitor actinomycin D and the translation inhibitor cycloheximide both completely block assayable BPA production. Not only sBPA but also membrane-associated BPA was reduced (see Table III), suggesting that the generation of either form of the factor requires active mRNA and protein synthesis. In contrast, DNA synthesis does not appear to be required for elaboration of these activities (see Table IV). This result is consistent with the previous experience that, whereas lymphocyte exposure to lipopolysaccharide or plant lectins augments growth factor levels in CM, it is not essential for their production (19). Accordingly, lymphocyte mitogens may increase growth factor synthesis similar to their selective augmentation of the level of synthesis of other cytosolic proteins $(38,39)$, without requiring the cells to undergo replicative DNA synthesis, entry into $S$ phase and ultimately, mitotic division.

Preliminary characterization of BPA shows it to be an integral membrane glycoprotein that is similar to other hematopoietic growth factors in molecular mass and charge heterogeneity $(2,3,19,20)$. Since remodeling and terminal glycosylation of oligosaccharide units of many glycoproteins take place in the Golgi apparatus, the effects of monensin on BPA expression were assessed. Marked reductions in both total and specific activities of the factor in CM and plasma membranes prepared from monensin-treated cells (see Table II and Fig. 4) strongly suggest that production of bioactive BPA involves transport through and out of the Golgi complex. The importance of posttranslational processing is further supported by the finding that enzymatic deglycosylation of column purified BPA removes $>90 \%$ of bioactivity (personal observation).

Normal and neoplastic cells shed surface membrane components $(19,40-42)$. Exfoliation of plasma membrane constituents may mediate diverse cell functions, including communication with other cells within the proximal environment, selective release of lipids and proteins, activation of the blood coagulation system, and embryonic proteolysis (43). Shedding of gangliosides and other membrane components from the surface of neoplastic cells may be a mechanism by which these cells suppress antigen presentation (44), alter immune effector responses (45), and escape immune detection (46). We have observed that membrane vesicles shed from the surface of normal lymphocytes behave as carriers of signal molecules for hematopoietic progenitor/stem cells $(12,19)$.

Cholesterol, phospholipid, and protein compositions as 


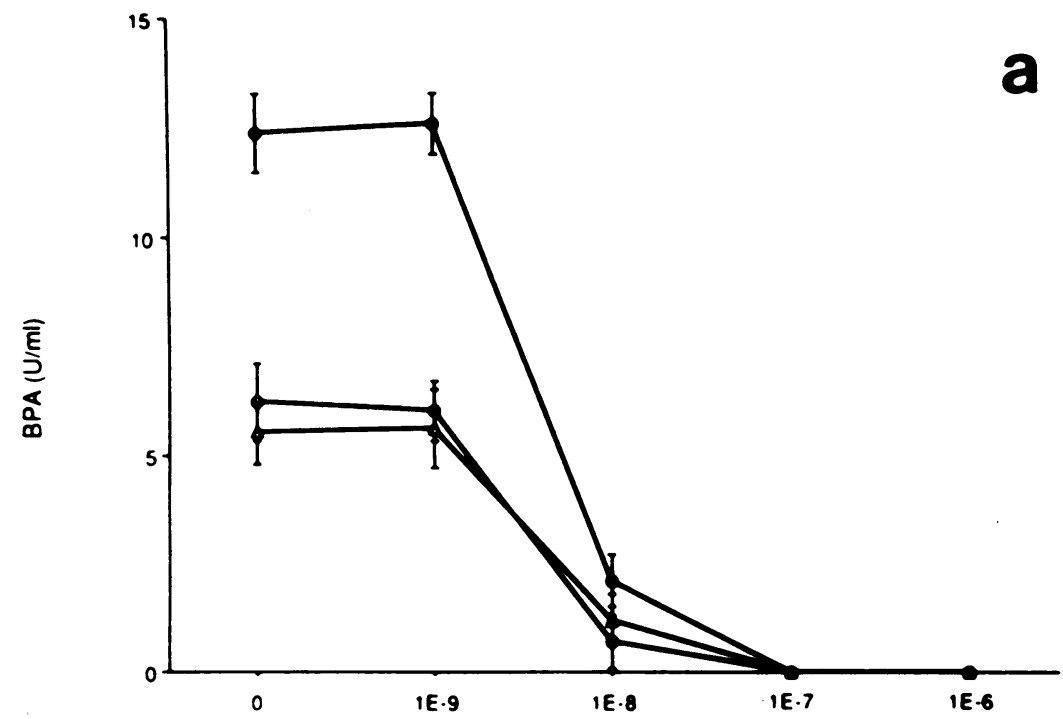

Monensin (M)

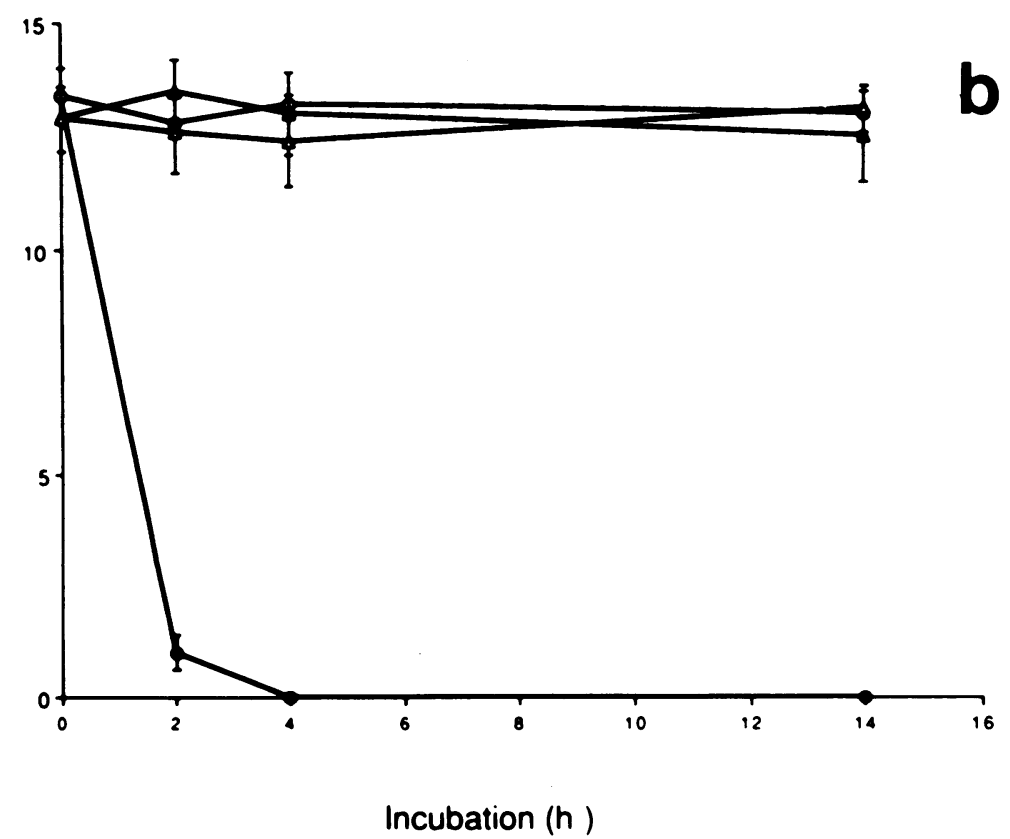

Figure 4. Effect of monensin on BPA production. (a) Mean $\pm \operatorname{SE~tBPA}(\bullet), \operatorname{mBPA}(0)$, and sBPA $(\Delta)$ levels in medium condition by $B$ lymphocytes treated for $120 \mathrm{~min}$ at $37^{\circ} \mathrm{C}$ with monensin. Activity is reduced to zero by exposure to of $10^{-7}$ or $10^{-6} \mathrm{M}$ monensin. (b) Mean \pm SE tBPA levels in medium conditioned by $B$ cells treated for the various times with $10^{-9} \mathrm{M}(\triangle)$ or $10^{-8} \mathrm{M}(\bullet)$ monensin. Also shown are BPA levels in medium that was prepared from untreated lymphocytes which was subsequently incubated for various times with $10^{-9} \mathrm{M}(\Delta)$ or $10^{-8} \mathrm{M}(\mathrm{O})$ monensin, and dialyzed exhaustively to remove the drug. Whereas pretreatment of $B$ cells with $10^{-8} \mathrm{M}$ monensin for $\geq 4 \mathrm{~h}$ abolishes all activity, exposure to medium conditioned by untreated cells for similar time periods does not alter tBPA levels (relative to control, $P>0.10$ at each time point).

well as fluidity properties of vesicles shed from murine and human lymphocytes are distinct from those of intact lymphocyte plasma membranes $(47,48)$. Therefore, rather than being a random process, cell surface exfoliation may be a directed activity (48). If true, then one would predict that surface shedding requires active cell metabolism and consumes energy. The results indicate that this is the case with regard to the release of mBPA from B lymphocytes. Both surface membrane exfoliation per se and mBPA expression by $\mathrm{CM}(\mathrm{P})$ were markedly reduced by pulse-exposure to metabolic inhibitors of cell metabolism (see Fig. 3 and Table II). There was no apparent delay in extracellular membrane vesicle formation over the $14-\mathrm{h}$ incubation used in this study, and cell viabilities immediately after drug exposure and at the time of CM harvest were similar to those of untreated cells. Interestingly, a recent report indi- cates that platelets which are incubated with 2-deoxyglucose and antimycin A fail to shed membrane vesicles in response to collagen or thrombin but show apparently normal vesiculation in response to complement (49), suggesting that in some cases, active metabolism is required for platelet vesiculation as well.

Several mechanisms have been thought to be involved in plasma membrane exfoliation (40). Cell surface proteases (50, 51 ) and phospholipases (52) may enzymatically modify the plasma membrane, resulting in extracellular vesicle formation. Results showing that the addition during conditioning of protease inhibitors, including leupeptin, aprotinin, TPCK, TLCK, and/or PMSF does not alter BPA levels in CM(P) (see Table I), suggest that release of the activity in association with vesicles is not likely due to proteolysis. Nevertheless, since other surface proteases (such as the acidic and metalloproteases) were not 
specifically inhibited, the possibility that proteolysis may participate in mBPA release from the cell membrane has not been completely excluded.

In addition, cytoskeletal proteins may play a role in extracellular vesiculation $(53,54)$. The investigators have previously reported that actin filament formation is necessary for surface exfoliation and mBPA expression by both intact lymphocyte plasma membranes and shed extracellular vesicles(54). Accordingly, microfilament integrity may be important for mBPA localization as an integral component of the plasma membrane. Since actin polymerization is an energy-consuming process (55), the possibility that cell metabolism is required for mBPA expression by plasma membranes was investigated. The results show that the specific activity of mBPA in extracts of intact plasma membranes is markedly reduced by metabolic inhibitors (see Table II), suggesting that intracellular trafficking and/ or insertion of growth factor into the plasma membrane requires metabolic energy. The relationship of soluble and membrane-bound forms of the factor is unknown but kinetic analysis of their appearance in liquid culture medium (see Fig. 1) raises the possibility that $\mathrm{SBPA}$ may be derived from $\mathrm{mBPA}$, an hypothesis that is supported by the finding that a monoclonal antibody can be used to immunoadsorb both SBPA and solubilized mBPA from solution (56).

In summary, we report that pulse-treatment of B lymphocytes with specific inhibitors of mRNA synthesis, translation, and posttranslational modification renders the cells incapable of producing and releasing the erythropoietic growth factor BPA. Exposure to inhibitors of energy-dependent cell metabolism results in impaired extracellular vesiculation and reduced activity per ug membrane protein. The data suggest a model wherein BPA production by lymphocytes is similar to hormone synthesis in endocrine cells, involving transcription, translation, and processing of the growth factor. Moreover, release of the growth factor as an integral component of extracellular, membrane-derived vesicles also requires cell metabolism, supporting the concept that exfoliation is a directed cell process that enables neighboring cells to signal each other.

\section{Acknowledgments}

This study was supported by grants DK-27071 and DK-31060 from the National Institutes of Health.

\section{References}

1. Torok-Storb, B. 1988. Cellular interactions. Blood 72:373-385.

2. Sieff, C. A. 1987. Hematopoietic growth factors. J. Clin. Invest. 79:15491557.

3. Metcalf, D. 1986. The molecular biology and functions of the granulocytemacrophage colony-stimulating factors. Blood. 67:257-267.

4. Dainiak, N., L. Feldman, D. Sutter, C. M. Cohen, and A. Najman. 1987. Support of erythropoietic growth by proximal marrow cell-derived processes. In Regulation of Erythropoiesis. E. D. Zanjani, M. Tavassoli, and J. L. Ascensao, editors, PMA Publishing Corp., New York. 127-140.

5. Dainiak, N. 1990. Classification of hormone and nonhormone growth factors. In Molecular Biology of Hematopoiesis. N. G. Abraham, G. Konwalinka,

L. Sachs, J. Wiederman, editors, Intercept, London. 445-454.

6. Najman, A., C. Baillou, X. Drouet, G. LeBlanc, L. Douay, N. C. Gorin, and G. Duhamel. 1985. Regulation of human peripheral blood BFU-E growth in vitro by leukemic B-lymphocytes. Br. J. Haematol. 60:643-650.

7. Uckun, F. M., D. A. Vallera, and S.-L. Wee. 1985. B-lymphocyte regulation of human hematopoiesis. J. Immunol. 135:3817-3822.

8. Dainiak, N., A. Najman, S. Kreczko, C. Baillou, J. Mier, L. Feldman, N. C. Gorin, and G. Duhamel. 1987. B-lymphocytes as a source of cell surface growthpromoting factors for hematopoietic progenitors. Exp. Hematol. 15:1086-1096.
9. Niskanen, E., J. Gorman, and P. C. Isakson. 1987. Hematopoietic precursors respond to a unique B-lymphocyte derived factor in vivo. Blood. 70:1784 1789.

10. Steiner, D. F., P. S. Quinn, S. J. Chan, J. Marsh, and H. S. Tager. 1980 Processing mechanisms in the biosynthesis of proteins. Ann. NY Acad. Sci. 343:1-16.

11. Steiner, D. F., G. I. Bell, and H. S. Tager, 1989. Chemistry and biosynthesis of pancreatic protein hormones. In Endocrinology. L. J. DeGroot, G. M. Besser, G. F. Cahill, J. C. Marshall, D. H. Nelson, W. D. Odell, J. T. Potts, A. H. Rubenstein, and E. Steinberger, editors, W. B. Saunders Co., Philadelphia. 12631289.

12. Dainiak, N., and C. M. Cohen. 1985. Regulation of human erythroid proliferation in vitro by leukocyte surface components. Ann. NY Acad. Sci. 459:129-142.

13. Dainiak, N., D. Sutter, and S. Kreczko. 1986. L-Triiodothyronine augments erythropoietic growth factor release from peripheral blood and bone marrow leukocytes. Blood. 68:1289-1297.

14. Dainiak, N., S. Kreczko, A. Cohen, R. Pannell, and J. Lawler. Primary human marrow cultures for erythroid bursts in a serum-substituted system. 1985. Exp. Hematol. 13:1073-1079.

15. Chance, B., G. R. Williams, and G. Hollunger. 1961. The inhibition of electron and energy transfer in mitochondria. III. Spectroscopic and separatory effects of uncoupling agents. J. Biol. Chem. 278:439-444.

16. Stryer, L. 1988. Biochemistry, 3rd edition. W. H. Freeman \& Co., New York. 412-413.

17. Pestka, S. 1977. Inhibitors of protein synthesis. In: Molecular Mechanisms of Protein Biosynthesis. H. Weissbach and S. Pestka, editors. Academic Press, Inc., New York. 467-533.

18. Tartakoff, A. M. 1983. Perturbation of vesicular traffic with the carboxylic ionophase monensin. Cell. 32:1026-1028.

19. Dainiak, N., and C. M. Cohen. 1982. Surface membrane vesicles from mononuclear cells stimulate erythroid stem cells to proliferate in culture. Blood. 60:583-594.

20. Feldman L., C. M. Cohen, M. A. Riordan, and N. Dainiak, 1987. Purification of a membrane-derived human erythroid growth factor. Proc. Natl. Acad. Sci. USA. 84:6775-6779.

21. Lowry, O. H., N. J. Rosebrough, A. L. Farr, and R. J. Randall. 1951. Protein measurement with the Folin phenol reagent. J. Biol. Chem. 193:265-275.

22. Udenfriend, S., S. Stein, P. Bohlen, W. Dairman, W. Leimgruber, and M. Weigele. 1972. Fluorescamine: a reagent for assay of amino acids, peptides, proteins and primary amines in the picomole range. Science (Wash. DC). 178:871872 .

23. Goldstein, A. 1964. Biostatistics: An Introductory Text. Macmillan Publishing Co., Inc., New York. 62.

24. Szabo, M. T., A. Hrabak, and F. Antoni. 1979. An inhibitory factor of DNA synthesis derived from the medium of short-time incubated human lymphocytes. Immunol. Lett. 1:115-119.

25. Hall, D. J., J. J. O'Leary, and A. Rosenberg. 1984. Early synthesis of specific cytoplasm proteins is correlated with the rate of exit of lymphocytes from the resting state. J. Cell Biol. 99:1814-1821.

26. Sarmay, G., L. Istvan, and J. Gergely. 1978. Shedding and reappearance of Fc, C3, and SRBC receptors on peripheral lymphocytes from normal donors and chronic lymphatic leukemia (CLL) patients. Immunology. 34:315-321.

27. Liepins, A., and A. J. Hillman. 1981. Shedding of tumor cell surface membranes. Cell. Biol. Int. Rep. 5:15-26.

28. Bradshaw, R. A. 1987. The control of cell growth: The role of polypeptide growth factors and oncogene products. In Oncogenes and Growth Factors. R. A. Bradshaw and S. Prentis, editors. Elsevier, Amsterdam. 11-16.

29. Dainiak, N., G. Davies, M. Kalmanti, J. Lawler, and V. Kulkarni. 1983. Platelet-derived growth factor promotes proliferation of erythropoietic progenitor cells in vitro. J. Clin. Invest. 71:1206-1214.

30. Delwiche, F., E. Raines, J. Powell, R. Ross, and J. Adamson. 1985. Platelet-derived growth factor enhances in vitro erythropoiesis via stimulation of mesenchymal cells. J. Clin. Invest. 76:137-142.

31. Sytkowski, A. J., C. O'Hara, G. Vonasse, M. J. Armstrong, and N. Dainiak. 1990. Characterization of biologically active, platelet-derived growth factorlike molecules produced by murine erythroid cells in vitro and in vivo. $J$. Clin. Invest. 85:40-46.

32. Dainiak, N., and S. Kreczko. 1985. Interactions of insulin-like growth factor II and platelet-derived growth factor in erythropoietic culture $J$. Clin. Invest. 76:1237-1242.

33. Kurtz, A., W. Hartl, W. Jelkmann, and J. Zapf. 1985. Activity in fetal bovine serum that stimulates erythroid colony formation in fetal mouse livers in insulin-like growth factor I. J. Clin. Invest. 76:1643-1648.

34. Merchov, S., I. Tartarsky, and Z. Hochberg. 1988. Enhancement of human granulopoiesis in vitro by biosynthetic insulin-like growth factor I/somatomedin $C$ and human growth hormone. J. Clin. Invest. 81:791-797.

35. Pimentel, E. 1987. Transforming growth factors. In Hormones, Growth Factors and Oncogenes. CRC Press, Boca Raton, FL. 147-194. 
36. Dainiak, N. 1990. Hematologic manifestations of endocrine disorders. In Principles and Practice of Hematology. E. Benz, R. Hoffman, B. Furie, H. Cohen, and S. Shattil, editors. Churchill-Livingstone, New York. 1747-1759.

37. Feldman, L., and N. Dainiak. 1988. B-lymphocyte-derived erythroid burst-promoting activity is distinct from other known lymphokines. Blood 73:1814-1820.

38. Degen, J. L., M. G. Neubauer, S. J. Friezner-Degen, C. E. Seyfried, and D. R. Morris. 1983. Regulation of protein synthesis in mitogen-activated bovine lymphocytes: analysis of actin-specific and total mRNA accumulation and utilization. J. Biol. Chem. 258:12153-12162.

39. Hall, D. J., J. J. O'Leary, and A. Rosenberg. 1984. Early synthesis of specific cytosolic proteins is correlated with the rate of exit of lymphocytes from the resting state. J. Cell Biol. 99:1814-1821.

40. Taylor, D. D., and P. H. Black. 1986. Shedding of plasma membrane fragments: neoplastic and developmental importance. In The Cell Surface in Development and Cancer. M. S. Steinberg, editor. Plenum Publishing Corp., New York. 33-57.

41. Doljanski, F., and M. Kapeller. 1976. Cell surface shedding: the phenomenon and its possible significance. J. Theor Biol. 62:253-270.

42. Sims, P. J., and T. Wiedmer. 1986. Repopulations of the membrane potential of blood platelets after complement damage: evidence for a $\mathrm{Ca}^{++}$-dependent exocytotic elimination of $\mathrm{C}^{2} \mathrm{a}^{-9}$ pores. Blood. 68:556-561.

43. Dainiak, N. 1990. Role of cell surface-associated molecules in normal and malignant cell proliferation. In Growth Regulation and Carcinogenesis. W. R. Paukovits, editor. CRC Press, Boca Raton, FL. In press.

44. Taylor, D. D., and P. H. Black. 1985. Inhibition of macrophage Ia antigen expression by shed plasma membrane vesicles from metastatic murine melanoma lines. J. Natl. Cancer Inst. 74:859-867.

45. Ladisch, S., B. Gillard, C. Wong, and L. Ulsh. 1983. Shedding and immunoregulatory activity of YAC-1 lymphoma cell gangliosides. Cancer Res. 43:3808-3813.
46. Ladisch, S., S. Kitada, and E. F. Hays. 1987. Gangliosides shed by tumor cells enhance tumor formation in mice. J. Clin. Invest. 79:1879-1882.

47. van Blitterswijk, W. J., G. De Veer, J. H. Krol, and P. Emmelot. 1982. Comparative lipid analysis of purified plasma membranes and shed extracellular membrane vesicles from normal murine thymocytes and leukemia GRSL cells. Biochim. Biophys. Acta. 688:495-504.

48. Armstrong, M. J., J. Storch, and N. Dainiak. 1988. Structurally distinct plasma membrane regions give rise to extracellular membrane vesicles in normal and transformed lymphocytes. Biochim. Biophys. Acta. 946:106-112.

49. Wiedmer, T., S. J. Shattil, M. Cunningham, and P. J. Sims. 1990. Role of calcium and calpain in complement-induced vesiculation of the platelet plasma membrane and in the expression of the platelet factor Va receptor. Biochemistry. 29:623-632.

50. Roblin, R., I. H. Chou, and P. H. Black. 1975. Proteolytic enzymes, cell surface changes, and viral transformation. Adv. Cancer Res. 22:203-260.

51. Richert, N. D., and R. J. Ryan. 1977. Proteolytic enzyme activation of rat ovarian adenylate cyclase. Proc. Natl. Acad. Sci. USA. 74:4857-4861.

52. van der Bosch, H. 1982. Phospholipase. In Phospholipids. J. N. Hawthorne and G. B. Ansell, editors. Elsevier, Amsterdam. 313-358.

53. Emerson, S. G., and R. E. Cone. 1979. Differential effects of colchicine and cytochalasins on the shedding of murine B-cell membrane IgM and IgD. Proc. Natl. Acad. Sci. USA. 76:6582-6586.

54. Dainiak, N., M. A. Riordan, P. R. Strauss, L. Feldman, and S. Kreczko. 1988. Contractile proteins participate in release of erythroid growth regulators from mononuclear cells. Blood. 72:165-171.

55. Korn, E. D. 1982. Actin polymerization and its regulation by proteins from nonmuscle cells. Physiol. Rev. 62:672-737.

56. Dainiak, N., G. Warren, D. Sutter, S. Kreczko, and D. Howard. 1988. A monoclonal antibody to exfoliated surface vesicles that recognizes a membraneassociated erythroid burst-promoting activity. Blood. 72:989-994. 